\title{
On the concept of the New Literature in the Chinese Language in the visual field of world literature
}

\author{
Zhu Shoutong
}

Published online: 4 October 2011

(C) Akadémiai Kiadó, Budapest, Hungary 2011

\begin{abstract}
Modern Chinese Literature" has many similar descriptions such as "Modern and Contemporary Chinese Literature", "Chinese Literature in the 20th Century", and "New Chinese Literature". The concept of "New Literature in Chinese Language" is a best choice to define it, especially in the visual field of world literature. "New Literature in Chinese" contains modern and contemporary literature, together with "literatures in Taiwan, Hong Kong, Macau and overseas Chinese literature", or "international Chinese literature". "New Literature in Chinese" enjoys the advantage of furthest surpassing and even overcoming the regulations and restrictions of national plates and political regions, hence the New Literature studies can get rid of the politicized academic prediction and construct new paths in exploring the laws of Chinese aesthetic expressions. Just as the concept "English literature" should be understood as "literature in English" rather than "British literature", the concept of "New Literature in Chinese Language" is acceptable.
\end{abstract}

Keywords New literature in Chinese language $\cdot$ World literature $\cdot$ Chinese language

New Literature in the Chinese Language (漢語新文學) is a sort of the world literatures. But up to now, its discipline has been variously labeled the "Modern and Contemporary Chinese Literature", "Chinese Literature in the 20th Century", the "Literatures in Taiwan, Hong Kong Macao and Overseas Chinese Literature", or the "World Chinese Literature". They also appear in the Chinese official disciplinary catalogue as independent terms. These labels very often overlap each other, thus leading to ambiguities and confusions, especially to the international readers and researchers. As a result, scholars in the field are likely to get lost in the confusion and narrow down their scholarship and fail to establish their academic identity. Although there is no positive correlation between the academic identity and academic achievement, the failure to put these disciplines in array and achieve a integration within a broader framework will hinder the further development of the

Z. Shoutong $(\bowtie)$

University of Macau, Macau, People's Republic of China

e-mail: STZhu@umac.mo 
discipline. It is believed that the academic operations run under the guidance of the constructive rules and directive rules with the former being the core rules. The abovementioned labels of the New Literature in the Chinese Language are a result of flouting of the constructive rules, which will lead to the malfunction of the directive rules. As a result, the academic norms in the field of New Literature in the Chinese Language remain to be developed and perfected. This paper is an attempt to build up a norm-constructive and directive rules. What is common to the above-mentioned disciplinary labels is that the modern Chinese language is the language usage, a language which differs from the traditional Chinese. No matter whether they are produced in China mainland or produced overseas, this linguistic feature is what integrates them. By integrating the different labels into the literature in the modern Chinese language, the paper might paves the way for the further development and possible perfection of the academic norms in the field.

\section{The definition}

The Chinese New Literature (中國新文學) as an academic term, appeared in the May 4 period in the late 1910s and the early 20s of the twentieth century. It stood in contrast to the Old Literature in Chinese, which it intended to overthrow and replace. The term had been used by Hu Shi, Lu Xun, Zhou Zuoren, Zhu Ziqing, who were both masters of the New Literature and the very first researchers in the field. In the late $20 \mathrm{~s}$ and early $30 \mathrm{~s}$ of twentieth century, the Chinese New Literature as a course appeared in the curriculum of Chinese universities and schools. Zhu Ziqing taught Research in Chinese New Literature in Tsinhua University while Zhou Zuoren lectured on the Origins of the Chinese New Literature. The term was officially established in 1935 when Anthology of New Literature in Chinese ${ }^{1}$ were published. With the passage of time, it was gradually replaced by a new term Modern Chinese Literature (中國現代文學), which seems to be more accurate and academically sound. The latter has founded wide acceptance after the founding of the People's Republic of China, because the term both underscores the new political entity and the temporal feature. As its counterparts, the Classical Chinese Literature and Literature in the Late Qing Dynasty and Early Republican period cropped up as disciplinary terms.

In fact, in the transition from the Chinese New Literature to Modern Chinese Literature, besides the political and temporary factors mentioned, the social and cultural mentality of a particular era also played a role. When the Chinese New Literature was newly established, there were a team of scholars who put forward the concept Literatures in Modern China (現代中國文學) to rival the term. The earliest and most representative among them was Qian Jibo who published A Literary History of Modern China in 1933, which should be the forerunner of the Modern Chinese Literature. Dissatisfied with the New Literature, Qian complained that the so-called New Literature was the result of "Hu Shi's pompous propaganda with the goal to achieve fame for himself." He disagreed with Hu that Chinese literature after the founding of Republican China should be termed "New Literature". Instead, he claimed, the so-called "New Literature" was only a part of the overall literary scenario. The major achievements in the field were made in the sphere of classical literature. The writers in both spheres were modern literary writers. It is important to point out that, Qian's substitution of Modern Literature for New Literature was not due to his awareness that the concept the Modern Literature would be in a better position in the development of the literary discipline. Instead, it was due chiefly to the popularity of the

1 Zhao (1935). 
word "modern" in the 1930s' China. It was an era when China tortured by continuous wars opened its door wide for a short time to the outside and Shanghai as China's cultural center was permeated with everything associated with modernity. At that era, the English word "modern" as well as its Chinese term 摩登 were the key words of the cultural domain. As a part of the modern culture, Modern Literature came to the forefront. It had become inevitable that it was going to replace the New Literature. As is known, the journal Modern Literature was one of the most important journals in the 1930s. It is more symbolic that its precedent was entitled New Literature. The change of key words signifies the transition of disciplinary terms. It is said that Yang Zhensheng gave a lecture termed "Modern Literature" at Peking University in the 1930s. Without the academic standstill caused by the Japanese invasion, the works termed History of Modern Chinese Literature wouldn't come out as late as 1944.

Because of the social and cultural mentality, and then the requirements of political expression, there appeared a trend to replace the Chinese New Literature with the Modern Chinese Literature from the early 1930s. In the late 1950s, the Modern Chinese Literature finally prevailed over the Chinese New Literature. Paradoxically, the Contemporary Chinese Literature (中國當代文學) started to erode it soil. It was originally termed "New China Literature” (新中國文學) or “the Literature after the founding of the People's Republic”(建國后文學), which clearly signifies its ideological implications. The erosion climaxed around 1960 when the Contemporary Chinese Literature, with the help of the political advantage of the government, surpassed the Modern Chinese Literature in both scholastic and critical terms and became the more temporary dynamically influential critical term. It is obvious that the Contemporary Chinese Literature represents better a new era in both ideology and literature, which was so overwhelming that any scholar in the field couldn't possibly transcend it with his own subjective terms. While the Modern Chinese Literature is clearer in both denotation and connotation, the Contemporary Chinese Literature enjoys more political and ideological advantages. A balance should be arranged between them. After the combined efforts of the academic administrative bureaus and the literary researchers, a new term the Modern and Contemporary Chinese Literature (中國現當代文學) emerged. It is obvious that it is a rather random and temporary combination of two terms. But ever since its emergence, it has been the most authoritative and more prescriptive concept in the field. Its dominance has been felt not only in China mainland, but also felt in Hong Kong, Macau and Taiwan and oversea Chinese communities.

In spite of its long-standing usage and dominance in the official academic catalogue, the term Modern and Contemporary Chinese Literature is not at all sound, because it seems to us that it can cover the literatures of other ethnic nationalities in China. China has always been a country with lots of nationalities. "The Chinese as a nation, from its very beginning is an integration of lots of tribes and nationalities (including ancient tribes and nationalities and the present day 56 nations.) In the past thousands of years, Chinese history is a history of interactions and exchanges among these nations, thus unfolding a most colorful and most vigorous cultural panorama. So China is a nation of nations, blood-bound and culturally bound." It follows that "the literatures in the Chinese Language, whether it is the traditional literature or the new literature is only part of the literatures of China as a nation, although it is the major part." ${ }^{2}$ The scholars in the field of literatures in China have consciously or unconsciously narrowed down their academic domain. As a result, the nature and the name don't fit.

2 Yang (2006, p. 17). 
Diachronically speaking, the Modern and Contemporary Literature will literally cover the traditional literary creation in the twentieth century. This is what Qian Jibo did in his book, which will leads to problems in the internal relationship of the literature in China, because the nature and name won't fit for a second time. This is a second dilemma researchers have to face. Based on the two dilemmas discussed above, the so-called Modern and Contemporary Chinese Literature is, in fact, the New Literature in the Chinese language (汉语新文学).

As a matter of fact, the past decade has seen considerable efforts in instituting the notion of the New Literature in the Chinese language. The consensus is about to be reached. At the end of 2003, a seminar was arranged by the editorial panel of The Academic Studies of the Southeast China. "Chinese Literatures in the World was subject to an open-ended interpretation." The paper "A Tentative Notion: The Literature in the Chinese Language" explores the possibility and necessity to use the notion "The Literature in the Chinese language" from a special perspective, the perspective of the external relationships of the so-called Modern and Contemporary Chinese Literature. ${ }^{3}$ Although Taiwan, Hong Kong and Macao are indispensable parts of China, the literatures of the above regions have been excluded in the field of the Modern and Contemporary Chinese Literature. It is embarrassing to note the both peripheral and privilege status of the literatures of the above regions in the past academic understanding and practices. It is also the case for overseas Chinese literatures. As a result, the Modern and Contemporary Chinese Literature as well as the later World Chinese Literatures are not proper and inclusive terms. The Literature in the Chinese language is an attempt to integrate the various terms. But its domain is not as clear-cut and too broad as the New Literature in Chinese language when the notion the Modern and Contemporary Chinese Literature is challenged. As for the notions such as Literature in the Chinese language in the twentieth century and the Literature in the Chinese language in modern China, although they embody the recent institution of the Literature in the Chinese, they are still not inclusive enough spatially and temporarily. The problem lies in the fact that the literature (in fact it is the old-style literature in Chinese) will be excluded. The redundancy of the terms is another problem.

In fact, the legitimacy of the Modern and Contemporary Chinese Literature has long been questioned and there have been many attempts to modify it. A good case in point is A List of the History Books of Chinese Literature edited by Chen Fei. There are 184 books listed, among them only 4 are entitled "The Modern and Contemporary Chinese Literature", 22 are entitled "New Literature", 93 are entitled "Modern Literature", and 53 are entitled "Contemporary Literature", 12 are entitled "The 20 Century Chinese Literature" or "Centennial Chinese Literature". All these terms overwhelm the most popular and official term the Modern and Contemporary Chinese Literature in both number and proportion and "The Modern and Contemporary Chinese Literature" and "The Chinese New Literature" are the choice of the most books. ${ }^{4}$ The statistics reveal that most scholars are well-aware of the sloppiness of term, but they don't openly challenge it. Their gesture might be a reflection of sophisticated taciturnity, a servile obedience to official norms or deplorable negligence.

Such mentalities lead to the institution of the Modern and Contemporary Chinese Literature as an academic concept and the name of a discipline. In spite of its lack of seriousness and logic, it has long been established and it has long guided the academic studies and the development of the discipline, resulting academic inertia which seems hard

\footnotetext{
${ }^{3}$ Zhu (2004).

${ }^{4}$ Chen (2004, pp. 2092-2106).
} 
to overcome. It is high time for the academia to overcome the academic inertia courageously and take the discipline, its concept and name, very seriously. Mistakes ought to be corrected.

The only concept and term which can comprehensively cover the above-mentioned concepts and terms and will not lead to chaos and ambiguities is "the New Literature in the Chinese Language". Based on the linguistic facts of literary creation, it delimits the boundary, clearly and strictly, of the New Literature, reveals, self-evidently, its connections and differences with the Old Literature in the Chinese Language and demonstrates its relationship and its heterogeneous nature, when compared with other literatures in other languages.

\section{Theoretical advantages}

The literary domains defined according to nation, races or groups, though strongly ideological, basically don't need the motivation of ideology, and often turns out to be a natural academic choice. Therefore, in the above concepts listed about Chinese new literature, those with the words like "China" or other political system takes up the majority. These definitions of literary domains based on nations or governments are self-evident if it is not due to the fact that political or historical reasons complicated the relationship between the notion of nation and that of region. However, no matter how natural the process of the defining and conceptualizing the literary domains based on nation or regime, or how complete the retreat of the ideological factor in this process is, once established as academic concepts or names of subjects, these definitions inevitably enter the systemization of academic management or the institutionalization of higher education, which consequently are rendered certain political connotation in accordance with the ideological backgrounds.

Though the ideological factor and political connotation can facilitate the literary researchers in perceiving and evaluating the spiritual value of certain regional literature at a certain time, a loose grasp of them can also give rise to certain influences on academic rationality, and artificially divide the united literary creator of the same "SpeechCommunity" into various "political Community" plates with fissures and gaps.

According to the linguistic theory of Leonard Bloomfield, "Speech-Community" refers to the groups communicating with the same language, which obviously contradicts "political Community" (like nations). ${ }^{5}$ Literature is a form of art created by linguistic thinking and presented through the carrier of language. The property of literature as "Speech-Community" is bigger, more obvious, and more important than its property of "political Community", no matter seen from the interior situation of the creation or the outer effect of acceptance. Only under certain historical circumstances, like facing the fall of the nation and other disasters, will the creation of the literatures naturally arouses the sense of nation and political passion. Generally, the literary creators find it hard to turn to this "Grand Narration"; rather, they would submerge in the cultural meaning of certain social life to meditate upon and represent the personal aesthetic experience of the time, which would not affect the integrity of the same "Speech-Community" because of the different nationalities or political regions. In fact, even in times of sufficient sense of nation and political consciousness, like China's anti-Japanese war, there was no clear national gap or regional fissures either in mainland China or in Taiwan, Hong Kong or Macau even the remote south Pacific regions; all the Chinese literary creations are full of the same passion,

\footnotetext{
5 Li (1991, p. 36).
} 
which represents the integrity of "Speech-Community" of the contribution of Chinese to literature. Proved by the outer practice of literary acceptance shows that generally what literature brings to the reader first is not the nationality of the author or the consciousness of nation or groups in the works, but the language used to think, create and present as well as its language style. Linguists observe that a "Speech-Community" might contribute to the world a unique yet united language style. Thus it can be seen that a literature as an academic concept is better grouped on the basis of "Speech-Community" instead of defining it on national or political communities.

Compared with other concepts, "New Literature in Chinese language" enjoys the advantage of furthest surpassing and even overcoming the regulations and restrictions of national plates and political regions, hence the New Literature studies can get rid of the politicalized academic prediction and construct new academic paths in exploring the laws of Chinese aesthetic expressions. Sociological studies show that a person's name usually functions as a hint or correction to the shaping of his character. So do the academic concepts and names of the disciplines. An influential academic concept or the name of a discipline will imply or emphasize its academic expectation through its embedded key words or its tension, thus functioning as a self-evident model for the respective academic researches. An academic concept with the key words of "China" will certainly reinforce the national consciousness in the academic expectation, while that with the key words of "modern" or "contemporary" etc., will surely introduce the political connotation and the huge changes of the times.

The academic-minded people usually blame the ideological factor in literary studies, but this factor not only results from political control, but also results from those academic concepts centering on national motifs like "Modern and Contemporary Chinese Literature". Western scholars have observed that even in those nations claiming the academic and cultural avoidance of politics, the national or group consciousness in the academic concepts and names of the disciplines also fatally cause the politicalized academics and culture. Harold Bloom, who proposed the famous "Influence Anxiety" and "Creative Misreading" and other concepts of literary criticism, seriously pointed out the severe fact that "literary teaching has been politicalized in the universities of the world today", which took the educational situation of the USA as a reference. ${ }^{6}$ By "politicalization" here it refers to the improper intensification of national or group consciousness. In Bloom's views, a classical narration without the limitation of nation or groups could be cozy, in which he can freely talk about Homer, Dante, William Shakespeare, Miguel de Cervantes Saavedra, James Joyce, Samuel Beckett, Marcel Proust or Franz Kafka, who repeatedly demonstrated great creativity.

This contemporary scholar on western classics sadly discovered that the literary categories classified according to nations or groups instead of cultural phenomena only give rise to the academic regulations, which should be the most powerful of culture, dominated by the national or racial consciousness with the least cultural connotation. It is especially true in China, a political space always emphasizing on ideology. Particular literary contents and creation environment decide the fact that the so-called Modern and Contemporary Chinese Literature cannot avoid the ideological valuation, but this shouldn't become the reason for ideological interference into literary studies. Despite the various methods of avoiding the reinforcement of ideological flavor of literary studies, the evasion of national consciousness in academic concepts or names of the disciplines, and efforts to carry out the academic summary and probes from the linguistic and cultural perspectives can reduce the

${ }^{6}$ Bloom (2005, p. 2). 
ideological property of literary researches, or at least weaken the researchers' habit of ideological valuation formed under the suggestion or requirement of some concepts. Indeed, even a literature historicist without any political intentions, once realizes that his research of literary history is defined according to nations, is prone to have such a notion that a country's literary history is the complete book recording the most sublime achievements in the national spirits. However, once it comes to "the most sublime spirit of a nation and race", 7 the academic perspective will inevitably be led to the outside of literature and get involved in ideological criticism. Ideology is of course important to literary studies, but it is not the whole of it, and cannot be the only perspective for literary studies. Literary researches with more depth call for the revelation of internal laws of literature. Literature as a linguistic art is more closely related to linguistic forms, especially the aesthetic forms of linguistic expression and their development. This is the academic reason for choosing the advantageous concept of "New Literature in Chinese" after reflecting upon several concepts with protruding national consciousness.

Literature is the art of language, and all the literary issues can and should be traced back to the linguistic layer. So is the case with the new literature, the definition and academic illustrations should go beyond national consciousness to enter the Chinese language level. In his Requirements for the New Literature, Zhou Zuoren defined the ideal new literature, and one of the assumptions is that this kind of new literature "should not be racial, national, local or familial", but it "should belong to the humankind, as well as an individual." 8 The theoretical significance of this statement lies in its denying the national and racial bases for literary classification, despite the fact that it is still weak to replace or dilute the national property of literature with human common character and individuality. Actually the literary critic field is now more and more oriented to confirming that the cultural connotation of one literature often has deeper significance than its national consciousness, though literary scholars usually ignore another important question: any culture represented by literature has an unimaginably close relation with certain linguistic conveyance.

Indeed, the literary archetype is not simply the representation of culture, because it can never go without the linguistic carrier. The cultural archetype of literature is necessarily inseparable from the linguistic expression as a carrier. The cultural archetype deposited and accumulated in a foreign literature is always closely related to the classic expression in that language; if translated into Chinese, many notes should be added to help understanding; besides, a lot of information, its symbolic meaning and aesthetic flavor of this cultural archetype will face fragmentation, deformity and loss. It is the same with the cultural archetypes in Chinese literature to the foreign readers. Because certain language brings certain information and image of cultural tradition, high-level literary communication among different languages becomes a rather complicated issue. Therefore, those theories of "literary in-translatability," though radical, are somewhat reasonable. An extension of this reasoning seems to lead to challenge the influential Goethe "World Literature" theory, but this challenge is not equal to unscrupulousness or unorthodoxy. Since scholar Durisin of Slovak published his monograph Theory of Inter-Literature Process, the "world literature" theory that transcends the linguistic prescription began to receive increasing questioning, and people are concerned about Durisin's "inter-literariness" theory, and the symbolic dividing line of the inter-literature is of course language and culture. ${ }^{9}$ Therefore, the first question of "inter-literariness" facing Chinese new literature

\footnotetext{
7 Zheng (1999, p. 5).

${ }^{8}$ Zhou (2001, p. 16).

9 Ďurišin (1989).
} 
researchers should not be whether it belongs to "modern and contemporary Chinese literature", but whether it is written in Chinese and whether it demonstrates the cultural information and cultural identity conveyed by Chinese language.

This is the reliable academic revelation of the inner laws of literature, which shows that language always acts as a decisive factor whether for the historical form or for the value form of literature. Thus, the differentiation of "inter-literariness" is more accurate and deeper when based on language categories rather than on nations or political spaces. The reasons can be analyzed from the perspectives of the natural context, style and cultural community.

In the first place, the same language naturally forms the same context, and literature written in the same language objectively forms a natural integral whole that cannot be divided by national classification or political alienation; therefore, the same kind of language (viz., the same "Speech-Community", rather than the same nation or the same political entity) becomes the criterion of the categorization of the same literary "community". All the literature written in modern Chinese language, no matter it is in the mainland or in Taiwan, Hong Kong, Macau or other political regions, no matter it is published in China or overseas, all forms an integral and inseparable "New Literature in Chinese language." The national or political division is only needed under the critic contexts of ideological analysis or the summary of local color. What's more, to a researcher of New Literature in Chinese, even a Chinese, this kind of categorization shouldn't bring any sentimental pleasure or represent the rational of academic logic.

Secondly, the obvious consistency of the same language in the flavor, aesthetic feeling and symbolic interest in literary expression forms the feature of this literature; this kind of literary style and aesthetic characteristics often can make more essential and integral contributions to the accumulation of human civilization than the national literature or folk color in a common sense. Some linguists definitely believe that the overall style of a language is completely in accordance with the national culture of this language: "Language style first refers to the total of all its differentiating features of a certain language among all the languages of the world. This can also be called the national style of a language." ${ }^{10}$ The aesthetic experience and accomplishments require various language forms, even all the language forms, to demonstrate. In this huge and abundant accumulation, literature in Chinese objectively appears in uniform and differs from cultures of other languages; as long as they are not expert Sinologists, for the international readers, the Chinese literary works they read, appreciate and accept are the contributions of Chinese language. They neither need, nor could they judge whether the Chinese works are from the Mainland China or Taiwan, Hong Kong, Macau or places out of China. In fact, as far as the new literature is concerned, the Chinese writing all over the world bears and develops the great tradition of "May 4th" New Literature. The huge aesthetic expressiveness and the gradually maturing style of modern Chinese brought by this tradition is more and more obviously embedded into the aesthetic memory of human civilization, and each writer in Chinese from different regions makes his contributions and shares the glory.

In the third place, the so-called national manner (in China it is usually called "China manner") or folk color that forms this kind of contributions to human civilization is but the linguistic representation of the formerly-stated cultural archetype. Any culture, especially the colony culture represented by literary works, is mainly conveyed through linguistic expression and portraiture; culture has different forms like national, racial, social forms, etc., but the most practical culture form is the interest and flavor of a "community"

${ }^{10}$ Wang (1994, p. 110). 
conveyed by the same kind of language, that is, the cultural identification of the same language; "Language and culture were not, Herder argued, merely aspects of the social environment within which people made their lives, they were constitutive of their very identity." ${ }^{11}$ Culture as the essence of people's identification is still conveyed and demonstrated through language. Thus, the essence of a nation's cultural identification finally returns to language.

Driven by various mentalities, many immaterial cultural heritages of China's traditional civilization are understood or interpreted as the common heritage of different nations in East Asia, but the spiritual and cultural heritages that are expressed in Chinese, namely texts, cannot be plundered by any other races of other languages. With Chinese as the rigid carrier, the splendid cultural traditions like Confucius doctrines will not be able to be included in other cultural systems. As an art of language, literature shows the most lively part of the cultural identification in one linguistic community, and the national manner and cultural style represented in literature is finally fulfilled by language itself.

In different regions New Literature in Chinese language may turn out different social environments and life experiences, but the theoretical basis even ethical basis for the aesthetic treatment of such environment and experience and the value judgment is still the new cultural customs and the respective innovative thinking that is closely related to the "May 4th" new literary traditions and condensed in modern Chinese language. In spite of the indelible influence of exotic cultures and literature on the new culture and new literature, modern language and its respective thinking in Chinese have made admittedly creative transformation through literary creation. Those left as particular spiritual heritage must be the finished product of the classic expression. Though the Chinese word "you mo (humor)" comes from "humor", it has been creatively transformed when expressed in modern Chinese, the Chinese information makes it no longer the equivalent for the Western "humor", and no other words in Chinese can evoke the same rich and full image. This is but a typical example of the cultural influence on vocabulary, and the creative transformation reflected in personal portrait, scenario depiction and narrative strategies are more common. In the early 1980s, literary historicist Tang Tao 唐㢷 made the following incisive statement on the phenomenon that western literary influence should fit the language style of Chinese: "There is a natural elimination process when the Western thoughts and foreign forms are combined with the aesthetic habits and art interests of the Chinese people...it is not unprecedented in the literary history that the inability to fit the Chinese language and life causes failures." ${ }^{2} \mathrm{He}$ listed as examples the undigested symbolic poetry of Li Jinfa 李金发 and the introduction of sonnets that ended in failure.

Due to the profoundly and remarkably decisive function of language for the quality of literature and the "inter-literature" relationship, when a literature is defined as a science or a discipline, the linguistic categorization should be done first; only under this premise can other qualities be reckoned with. This is the logic and reason for the more appropriate and more scientific concept of "New Literature in Chinese language". This is also the academic advantage of this concept in comparison with other present concepts like "Modern and Contemporary Chinese Literature." The New Literature in Chinese language, according to the theory of genetic epistemology, represents the essence of Chinese colloquial literature. What its mature history and its status of development demonstrate are still the improvements of art form and aesthetic capability shown in modern literature in Chinese. Therefore, practically speaking, designing and initiating the concept of "New Literature in

\footnotetext{
11 Poole (2003, p. 270).

12 Tang (1989, pp. 22-23).
} 
Chinese language" from the perspective of the Chinese language are in accordance with the historical situation and the developing trend.

\section{Practical value}

As an academic concept, New Literature in Chinese language is firmly supported by a strong theoretical base; as a separate discipline, it enjoys significant practical value. During its infancy, New Literature in Chinese language unprecedentedly highlights the importance of language itself and while as it grows up, the dispute is virtually focused on the choice between the classical and vernacular. The historically new elements of New Literature in Chinese language depend on the aesthetic construction of modern Chinese language. As a matter of fact, differentiating between literatures by using the language as the criterion, a practice which turns out feasible in the academic field and educational undertaking in China, has been widely adopted and recognized as being efficient in the concept design and application of foreign literatures. From the linguistic perspective, New Literature in Chinese language, in accordance with its historical development and contemporary expansion, integrates domestic and overseas writings in Chinese and reflects the mood shared by all the Chinese writers around the world. More importantly, the concise notion, with its powerful academic tensile force, is able to cope with the trend of development in modern Chinese writings in different locations and at different time, with all of them being combined into an academic integrity.

In terms of theory, the cultural archetype of literary representation is inseparable from the language which serves as the carrier, therefore, the most reliable criterion evaluating various categories of literature lies in the language itself; in terms of facts, the decisive role played by the modern language in the formation and development of the New Literature fails to receive due recognition. Diachronically, the substantial development of the New Literature normally finds its best expression in the improvement of artistry and craftiness manifested by the modern Chinese literature. The improvement, however, is always accompanied by the increasingly fierce debate on the issue of the Chinese language. Synchronically, New Literature in Chinese, in different regions or even different countries, displays similar Chinese language strategy and artistic level during the same period. The former reveals the language as the quintessence embodied in the notion of "New Literature in Chinese language" while the latter demonstrates the excessively high degree of crystallization in the notion of "New Literature in Chinese language" beyond regional constraints, both of which jointly explain the historical reasonableness and practical feasibility of the concept.

Researchers could notice that the birth and initial development of the New Literature should be attributed to the widespread application of vernacular Chinese. During May 4th Movement, the New Literature, which breaks from the conventional old Chinese literature by abandoning the bondage of deeply ingrained classical Chinese in a high-profile fashion, is catapulted to the prominence. Therefore, the emergence of the New Literature, in terms of its form and appearance at least, benefits from the victory of language revolution from classical to vernacular. New language, first and foremost, is the primary indicator of the New Literature. As a result, $\mathrm{Hu}$ Shi is always inclined to summarize the achievement of the New Literature from the perspective of the contribution made by vernacular Chinese. Indeed, the New Literature exponents have reached the consensus that the ideological reform should be prioritized, however, why should the ideological reform relate with literature? The answer lies in the fact that literature is the instrument that disseminates 
thoughts and ideas. As the content of Old Literature is enveloped in classical Chinese, some radical forerunners of the New Literature used to advocate "eliminating the Chinese language", a practice Cai Yuanpei 蔡元培 believes is hard to implement. However, he deems it practical to eliminate classical Chinese. In order to encourage people to embrace new ideas and concepts, first of all, the habit of using classical Chinese should be removed, meanwhile, the way of thinking in vernacular Chinese filled with modern atmosphere and messages of world civilization should be consolidated. ${ }^{13}$ Therefore, ideological and social reform entails the construction of the New Literature which in turn depends on the modern language, i.e., vernacular Chinese in the common sense. This is a dynamic quality and inborn mission of New Literature in Chinese language. With regard to the language quality and its relationship with the mission in the New Literature, the seemingly superficial understanding achieved by the forerunners explores deeper than the criticism put forward by the successors. Initially advocating vernacular Chinese, Hu Shi later on has it elevated to "the national language" (国语) for further discussion, equating "the national language of literature" (文学的国语) with "literature of the national language" (国语的文学) in a certain sense of ideological seriousness and prospective regulation. Obviously, his concept of "literature of the national language", apart from insisting on the usage of vernacular Chinese, lays emphasis on its popularization, which endows the notion of "New Literature in Chinese language" with self-explanatory implications in terms of the language regulation. His plain yet famous concept of literary evolution known as "each generation has its own literature" 14 is focused on the language which evolves from classical to vernacular, with the former eventually being replaced by the latter. His works entitled The History of the Vernacular Literature, in his own words, reveals such an unpretending academic issue in line with the concept of evolution, i.e., when does classical Chinese die? ${ }^{15}$ His long-term concept decidedly defines the quality of the New Literature: "It is imperative that vernacular Chinese be used if the New Literature is expected to emerge in China, express the meaning as well as emotion in modern times and represent the degree of social civilization." ${ }^{16} \mathrm{Hu}$ Shi is not alone in making the statement above, his ideological description and theoretical finding are shared by the New Literature exponents. It is generally acknowledged that $\mathrm{Hu}$ Shi devotes more efforts to advocate vernacular Chinese and his major contribution to the New Literature lies in the language reformation while his contemporary Chen Duxiu lays more emphasis on the revolution of literary content. However, the initial driving force of New Literature in Chinese does not and cannot analyze the literary content and language form in such a pedestrian manner. Chen Duxiu, for example, argues that vernacular Chinese can not be separated from the New Literature, which essentially means "the vernacular of literature." 17 According to him, the construction of the New Literature, first of all, depends on the advocation of vernacular Chinese. In this regard, he adopts a firmer stance than does Hu Shi, who hopes to initiate a debate concerning the reformation of vernacular Chinese and "welcome comments and criticisms". ${ }^{18}$ Chen Duxiu, however, flatly rejects such an ambiguous attitude by claiming that "revolutionalizing classical Chinese and establishing the authority of vernacular Chinese by no means allow for public

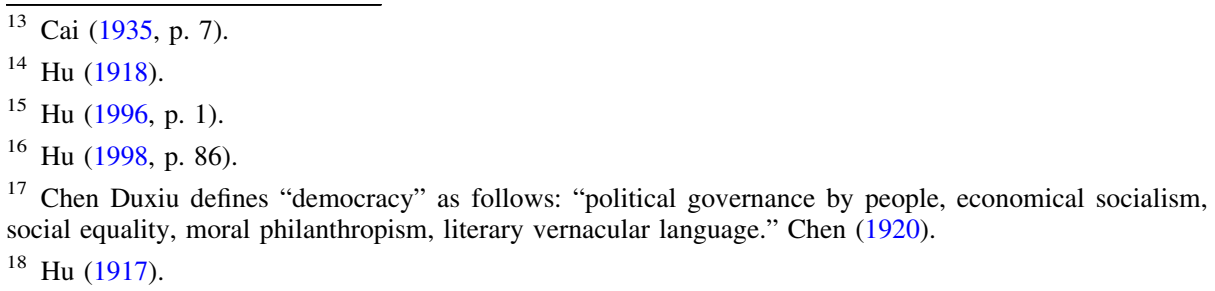


discussion and criticism". ${ }^{19}$ Obviously, he displays stronger determination and greater enthusiasm than $\mathrm{Hu}$. Chen sponsors vernacular Chinese by issuing such a precursory newspaper The Anhui Newspaper in Vernacular Chinese (安徽白话报). Furthermore, he promotes the education in vernacular Chinese and defines it as "the colloquialism popular nationwide" ten years earlier than $\mathrm{Hu}$.

The circle of literary study does not tend to approach the birth of the New Literature and the New Literature Movement from the perspective of the language itself, thus leading to such a significant historical fact being covered, i.e., in a series of disputes concerning literary revolution, both parties, representing the New Literature and the Old Literature respectively, concentrate more on the linguistic strategy than on open and modernized ideological as well as cultural concepts.

May 4th Movement witnesses highly frequent debate over the language in New Literature in Chinese language, which not only helps to establish the legitimacy of the modern Chinese language as the medium of literary representation, either subjectively or objectively, but also provides the New Literature writers with the stimulus, both positive and negative, to continuously improve the artistry and proficiency in using the modern Chinese, thus accelerating the maturity of vernacular literature and increasing the overall standard of New Literature in Chinese. At the initial stage in the campaign to advocate vernacular Chinese, many including Zhang Shizhao clamor about the difficulty to try the vernacular, however, very few writers are unable to manage the vernacular at the end of the 1920s- the only exception are those who complain out of the strong mood of resistance. A comparison between the vernacular poems in New Poetic Attempts 尝试集 by Hu Shi and relevant poems by $\mathrm{Xu}$ Zhimo reveals that such an amazing improvement in the artistry and proficiency of literary representation by the modern Chinese language should be directly attributed to the never-to-be-discontinued debate on the language of the New Literature.

The debate on the language of the New Literature does not come to an end in the wake of May 4th Movement. Virtually, it continues on an irregular basis with the discussion on "the literary dictatorship of the vernacular Chinese" during the late 1920s, "the popular language" arguments in the late 1920s and early 1930s, the Latinization campaign during 1930s as well as the exploration into the national form of the New Literature between the 1920 s and the 1930s. Even the dispute over the classical and the vernacular which appeared to have been settled long ago shows signs of revival in recent years. All of the historical facts above demonstrate that the New Literature in Chinese centers around a couple of key issues concerning the Chinese language. The moment the New Literature was born, and at every crucial phase of its evolution, the major contradictions are embodied in the language issue. In a time when the language issue remains not prominent may emerge ideological issues which, settled or not, do not exert any substantial impact on the development of the New Literature and its internal laws. Along the path in the development of New Literature in Chinese, every success and progress achieved in the expression of literary language and the creation of literary images are directly associated with settling the issues of the Chinese language in different forms and on different levels. Other issues like ideology and corresponding social and cultural connotations vary a great deal in different political regions, but the literary standard manifested in the Chinese language is similar synchronically. This is a strong testimony to the statement that the development of literature in Chinese builds up a direct link with the literary expression of the Chinese language and there is no such link between the New Literature in Chinese and ideology.

19 Chen (1918). 
It is true literature indeed depends, to a certain extent, on the ideological manifestation, which, however, is incapable of deciding the literary standard after all. The elements that directly reflect the literary standard include the linguistic artistry and proficiency in expressing the experience, mentality as well as emotion, and the improvement of both derives from the accumulated writing experience by literary figures on the one hand and theoretical debate over the literary language on the other hand. At the initial stage of the New Literature and in the 1920s and the 1930s, the literary practice of modern Chinese language, apart from extraordinary contributions made by a small number of linguistic and cultural masters, concentrates on the construction and removal of so-called "New Artistic Tone". Generally speaking, with the enhanced proficiency of vernacular Chinese, the expression of emotion as well as the mode of narration gradually improved. Such an increased literary standard cannot be separated from waves of discussions concerning the issues of the literary Chinese language. From the 1940s to the 1950s, the disputes over the language gradually fade into silence, thus resulting in the slow improvement of artistic level in the literary representation. In terms of the improvement in the artistry of literary representation and the proficiency in the Chinese language, New Literature in Chinese language witnesses the most conspicuous achievements during the 1920s and further progress, stability as well as maturity in the 1930s and the 1940s. Later on, the pace of development slows down, thus explaining why people always sigh with emotion that works of the highest literary standard nowadays does not match the brilliant literary classic written in the 1930s. Such a literary phenomenon, if depicted with a curve reflecting its historical development, echoes perfectly the degree of dedication to the issues of literary language by literary figures.

The development of New Literature in Chinese language at different historical stages, the capability of language manifestation in particular, remains level on in different regions and mirrors the same landscape of the time. Such a phenomenon can be attributed to the mutual influence of New Literature in Chinese in different regions, however, the root cause lies in the internal elements of modern Chinese language and the function of their growth, maturity and the development frequency. The latter may help to account for such a literary phenomenon, i.e., the literary standard and the landscape of the time manifested in the Chinese language are quite similar in the mainstream literature across the Taiwan Strait despite the escalating ideological conflicts. For example, the characters on both sides in the narrative literature feature powerful political coloring; the language used by the characters in the sense of their own roles have been deliberately exaggerated, and even the colloquialism adopted in the literatures across the Strait share a great deal in common. It came to readers as a big surprise that in spite of some differences in the idiomatic expressions in the wake of 30-year-long separation, literatures both in the mainland and Taiwan, almost at the same stage of development, are able to communicate efficiently with each other in term of the literary language description and representation. In recent years, new Chinese poems across the Strait have been filled with post-modern clamor, in which the strategy and order of the Chinese language experience some degrees of alteration.

However, the alteration reveals similar tendency inside or outside the mainland (Hong Kong, Macao, Taiwan as well as overseas). Such demonstrates the general situation and the basic rule in the comprehensive development of New Literature in Chinese.

The fact that the development of New Literature in Chinese language as a whole transcends the boundary of any specific country or region requires the academic circle, on the basis of reevaluating the intimate relationship between the Chinese language and the New Literature, to break down the existing system of concept centered around the national consciousness and construct or restore the system of concept with the language as the core. 
It is high time meanwhile to recognize and adopt "New Literature in Chinese language" as an academic concept and the name of a discipline. The concept accurately reflects the comprehensive development of New Literature in Chinese language in every aspect and bridges the man-made chasm or gap resulting from the state boundary, political alienation as well as regional distribution. Therefore, under the academic premise of the explicit consistency between connotation and denotation, New Literature in Chinese as a separate discipline, which transcends the geographical boundary, overcomes the political instability and expands more scientific and stable space for further development in the future academic circle, can be established in a harmonious, unified and balanced way. The increasing number of scholars specializing in New Literature has realized the academic tendency to grasp the literature in Chinese by removing the national or regional demarcation. Take the history of literary criticism for example, "The number of works on literary critical approach covering modern and contemporary time respectively has been increasing gradually since the 1990s, not only in the mainland, but also in Taiwan and Hong Kong. Recently, the academic circle has proposed compiling works on literary criticism during the twentieth century from a panoramic perspective that features the modernization program of literature as a whole by connecting both modern and contemporary in time and covering the mainland, Taiwan Hong Kong as well as Macao in space, i.e., a history of national literary critical theory." 20 Although "the whole nation" is a term widely accepted, "the whole of Han nationality" is more accurate in terms of the basic components of New Literature in Chinese language. Speaking of Han Nationality as a whole, overseas Chinese, in any case, should be taken into consideration. Therefore, the most reliable way of integrating writings in Chinese both at home and abroad is to create such an academic concept like "New Literature in Chinese language", a term with the Chinese language as the focus of attention.

In fact, the Chinese language provides domestic as well as overseas writers with a literary destination and spiritual support, therefore, its importance to the academic cognition of the New Literature is not purely theoretical. In specific contexts, the literary emotion towards the mother tongue can disperse or even replace fairly sensitive national consciousness. During the 1950s, Zhou Cezong, together with other overseas Chinese students in New York, established "the White Horse Literary Society" which is very active in the writings in modern Chinese, thus winning the compliment from $\mathrm{Hu} \mathrm{Shi}$, who describes it as "the third literary center of China", ${ }^{21}$ the others being situated in the mainland and Taiwan. Hu Shi does not include the literary phenomenon that occurs in America China's literature, let alone to say authoritative China's literature. What he tries to arrive at is that the White Horse Literary Society should be regarded as the third center of the New Literature writings in Chinese, which is on the equal footing with the other two respectively in the mainland and Taiwan. When making the statement above, "China" in his mind is no longer confined to an explicitly political concept, but a cultural and literary denotation. The fact that Hu Shih mistakenly refers to the Chinese language as "China" in his casual talk coherently demonstrates his blurred national consciousness and sharpened language sensitivity. As far as those overseas writers with Chinese ancestry are concerned, the only source of emotional comfort lies in the recognition of their literary works as part of the literature in Chinese.

The literary phenomenon involving New Literature in Chinese language is not alone that can be defined in terms of the language, the same is true with literature in ancient

\footnotetext{
${ }^{20}$ Huang (2005, p. 86).

21 Based on Zhou Cezhong's memoir. See Wong (2007, p. 614).
} 
China in the common sense as well as all the literary phenomenon generally referred to foreign literature by Chinese scholars. Furthermore, to define literature on the basis of the language turns out to be more scientific, more accurate and more powerful than that of nationality. Lu Xun compiled teaching notes when giving lectures on A Brief Literary History in China in Amoy University, which later on was changed into An Outline of Chinese Literature in Ancient Times as he moved to SunYet-Sen University, thus playing a significantly pioneering role in initiating the tradition of naming China's literature from the perspective of the language. Senior researcher Cheng Qianfan specializing in ancient Chinese literature, together with his student Cheng Zhangcan, both of whom particularly emphasize the importance of the naming of the academic concept, jointly compiled an ingenious book on the literary history a couple of years ago entitled The Literary History of the Chinese Language of the Chengs. ${ }^{22}$ Among hundreds of similar works, the Chengs, being exceptionally meticulous and conscientious, are able to establish their unique position with the literary history of the Chinese language as the key concept. Emphasizing the concepts of "Chinese national literature" or "the literary history of the Chinese literature" apparently sounds more accurate, scientific and appropriate than emphasizing the concept of "Literature in China" characterized by the nationality consciousness as the former ones modestly yet authentically demonstrate that their research object lies with the ancient literary works written in Chinese, excluding other literature in the Chinese history or written in other languages inside China. Indeed, part of the literary history in the Chinese language probably extends beyond the category of the literary history in China. For example, before Lin Chuanjia, Huangren embark on compiling The Literary History in China, German, Japanese and even Korean scholars have already produced several similar works such as the The Literary History in Zhina. However, Japanese and Korean scholars do not define literature in China in their works from the perspective of the Chinese language probably for the purpose of defending their own culture because a significant portion of traditional Japanese and Korean literature should be included as the literature in Chinese. Some of them hold it true that their own language and literature grow up in the combat with the literature in Chinese and as a matter of fact, some Koreans compose their own literary history revolving around the battle between the literatures in Chinese and in Korean.

In the mind of Chinese literature researchers and professors of literature in particular, the literary history around the world is classified in terms of nationality, such as British literature, American literature, French literature, Russian literature, to name just a few. Virtually the situation is particularly complex and a more popular practice to distinguish one literature from the other is to use the language as the criterion, hence literature in English, literature in French, literature in Russian. Only in this way the tradition of a variety of literature can be systematically arranged and their overall styles can be fully displayed. Literature in English in the common sense includes British literature, American literature, Canadian Literature as well as Australian literature, together with the literature in the regions under the British colonial domination. Chinese often get literature in English and British literature mixed up when it comes to understanding and translating literary works, thus making the complexity between these two terms even more confusing. It can be easily detected that both the author and the translator, amid the chaos, have made painstaking efforts to differentiate between "British literature" categorized by the nationality and "the literature in English" characterized by the language. Furthermore, it should be noticed that three-fourth of the books listed above adopt "literature in English"

22 Cheng (1999). 
as the key concept, a strong testimony of the public preference towards "literature in English" instead of "British literature". In fact, the concept "English literature", in most contexts, should be understood as "literature in English" rather than "British literature", which normally includes American literature and writings in English in other countries. For example, having noticed that "English literature" compiled by Charles Mills Gayley, The Classic Myths in English Literature and in Art ${ }^{23}$ does not refer to "British literature" alone, the Chinese translator put it into Ying Mei Wenxue (British and American literature), which, however, is still unable to cover everything in the book. Therefore, to translate it into Ying Mei Wenxue (British and American literature) as defined by the language instead of nationality fits into the explanation above. In the same line, such concepts like "literature in French", "literature in Russian" sound more inclusive and connotatively explicit compared to "French literature" or "Russian Literature". Sometimes literature covering several languages and extensive connotation can not be defined on the basis of nationality, for example, The Literary History of Sankrit by Jin Kemu includes the literary phenomenon in India, Pakistan and other regions where Vedaic and Pali are used, involving such religious beliefs as Buddhism, Jainism, Hinduism, Brahmanism, Islamism as well.

To define literature in terms of the language involved has become an academic fact and trend as well, reflecting the academic achievement people gladly recognize. In the face of such an academic fact, trend and achievement, there is every reason to juxtapose literature in Chinese with literature in English, literature in French, literature in Russian, literature in German, etc. in an attempt to broaden its historical as well as global literary horizon and increase its power of inclusion. It is highly necessary to define New Literature in Chinese within the field of literature in Chinese in general from the perspective of the internal state of literature in Chinese, the disparage in time when writers compose their literary works as well as the division of academic research. The concept "New Literature in Chinese", in comparison with traditional literature in Chinese, possesses a new style as well as tradition and assumes the responsibility of integrating new literature writing in the Chinese world. Not only academic practice, but also the development of academic discipline demonstrates that emphasizing the importance of language while undermining the national consciousness do not exert any negative impact. The title "Chinese language and literature" designed for undergraduates majoring in Chinese has been in use for dozens of years and its accuracy as well as scientific base have never been questioned or challenged. To have "New Literature in Chinese" as a branch discipline included into the discipline known as "Literature in the Chinese Language" seems more concerted and harmonious.

\section{Conclusion}

The institution and application of New Literature in Chinese as an academic concept and the name of a discipline has eradicated, in a neat manner, the chaos, and ambiguities of the previous concepts and names and it has substantially weakened the ideological anticipations and political implications which go inevitably with the conventional concepts and a state literature. The use of the term has claimed a bigger theoretical space for the discipline and its future development. It is true also that the application of the concept will bring about a series of theoretical and practical issues, which might be solved through accurate interpretation and scientific grasp of the concept of New Literature in Chinese language.

${ }^{23}$ Gayley (1911). 
The concept of New Literature in Chinese, with its advantage of eradicating the ambiguities and chaos brought by the concept of a state literature like the inclusion or exclusion of the literatures of the ethnic minorities in China, has brought about new problems which requires immediate and serious confrontation. For example, how to deal with the literary creations in Chinese by writers of the ethnic minorities in China and international writers is another problem. It is encouraging to see that this academic mission does not seem so formidable when we notice the relevant critical works of the Korean Xu Shixue, who writes poetry in modern Chinese. Such problems might crop up in future, but solving them will be not that difficult, while the problems and complications involved when using the conventional concepts and names are tougher to solve-there will be more academic missions they have to undertake but have failed to undertake, a fact which contributes the legitimacy and effectiveness of the concept and the name of the New Literature in Chinese language.

\section{References}

Bloom, H. (2005). Xifang Zhengdian (Western Cannon), A Chinese preface. Nanjing, China: Yilin Press.

Cai, Y. (1935). General preface, Zhongguo Xinwenxue Daxi (Anthology of Chinese new literature), the volume of theoretical construction. Shanghai, China: Shanghai Langyou Books Company.

Chen, D. (1918). Correspondence. New Youth, 3(3).

Chen, D. (1920). What is the new culture movement? New Youth, 7(5).

Chen, F. (2004). Hongguo Wenxue Zhuanshi Shuтu Tiyao (The summaries of the history books of Chinese literature). Zhengzhou, China: Daxiang Press.

Cheng, Q. (1999). Chengshi Hanyu WenxueTongshi. Shenyang, China: Liaohai Press.

Durišin, D. (1989). Theory of interliterary process. Bratislava, Slovakia: Veda.

Gayley, C. (1911). The classic myths in English literature and in art. Boston: Ginn.

Hu, S. (1917). Wenxue Gailiang Zhuyi (A modest proposal on literary reform), New Youth, 2(5).

Hu, S. (1918). Wenxue jinhua guannian yu xiju gailiang (The literary evolution concept and theatrical reform). New Youth, 5(4).

Hu, S. (1996). Baihua Wenxue Shi (The history of the vernacular literature). Beijing, China: Oriental Press.

Hu, S. (1998). A reply to Huang Jueshen on eclectic literary reform, Hu Shi Wenji (The collection works of $\mathrm{Hu}$ Shi). Beijing, China: People's Literary Press.

Huang, M. (2005). Xinwenxue Chuantong yu Jingdian Chanshi (New literary tradition and classical interpretation). Shi jia Zhuang, China: Hubei Education Press.

Li, K. (1991). Xiandai Jiegouzhuyi de Yike Mingxing-Bloomfield "Yuyan Xue" Daoyin (A star in modern structuralism - an introduction to Bloomfield's linguistics). Nanjing, China: Jiangsu Education Press.

Poole, R. (2003). National identity and citizenship. In L. M. Alcoff \& E. Mendieta (Eds.), Identities: Race, class, gender and nationality. Malden, MA: Blackwell.

Tang, T. (1989). Western influences and national style, Xifang Yingxiang yu Minzu Fengge (Western influences and national style). Beijing, China: People's Literary Press.

Wang, X. (1994). Language style and national culture. In X. Cheng \& Y. Ni (Eds.), Yuyan Fengge Lunji (A collection of papers on style). Nanjing, China: Nanjing University Press.

Wong, Y. (2007). The May 4 movement ignored: On Zhou Cezhong's new poetic movement overseas. Literature and Philosophy, (10).

Yang, Y. (2006). Tongxiang Dawenxue Shiguan (Leading to a broad view of literature). Hefei, China: Anhui Education Press.

Zhao, J. (Ed.). (1935). Zhongguo Xinwenxue Daxi (Anthology of chinese new literature). Shanghai, China: Liangyou Books Company.

Zheng, Z. (1999). Ben Zhongguo Wenxue Shi (Illustrated history of Chinese literature). Beijing, China: Beijing Press.

Zhou, Z. (2001). Zhou Zuoren Jingdian (Classic works of Zhou Zuoren). Haikou, China: Nanhai Press.

Zhu, S. (2004). Gainian: Shishuo 'Hanyu Wenxue' (A tentative notion: The literature in the Chinese language), Fuzhou: Academia of the Southeast China, Issue 2. 